\title{
Aha Malawi! \\ Envisioning Field Experiences that Nurture Cultural Competencies for Preservice Teachers
}

\author{
Patricia A. Talbot \\ Radford University
}

U. S. A.

This theoretical study uses the context of the writer's personal encounters in Malawi, Africa, to propose a conceptual model for creating diverse field experiences based on best practices in critical pedagogy, service learning, and the underpinnings of transformational learning theory, for the purpose of increasing the probability of meaningful and sustainable personal growth that impacts classroom practice over time. The visual framework proposed illustrates the overlap and the unique qualities of these three often-used perspectives for building cultural competencies for teachers and makes the case for incorporating all three when designing experiential learning opportunities with recommendations for how to do so.

\author{
Context \\ Transformational Learning \\ Critical Pedagogy \\ Service Learning \\ Aha Malawi: A Trifold Perspective \\ Implications and Recommendations \\ References
}

\section{Context}

\section{The Aha that Didn't Happen - 1980}

Some 30 years ago I was scheduled to be part of a new and innovative student teaching experience planned and administered by the College of Education at my rural, mostly White, public land grant university. The plan was to create a multicultural teaching model where elementary education students would have three student teaching placements in very diverse settings: one in a rural coal mine town, one in an inner city setting, and a third teaching on a Native American reservation in Arizona. At the end of the summer before heading south to the mining community in the far southwest corner of my state, I stopped in at the main office of the college, only to find a sign on the door indicating that our adventure had been cancelled and all candidates for the multicultural 
experience were to choose instead between the two local placements for student teaching. We were not told anything more about the fate of the program, but I came to learn over time that, like so many ambitious ideas in education, it was the victim of a funding shortage.

Our brief preparation for that thwarted experience and the anticipation of the opportunity to reach beyond my neighborhood to learn something about the world and its people never left me. A desire to deepen my understanding of the people of this planet remained as I spent the next 30 years in a single small-town community, working my way through a public school career as a teacher, counselor, and administrator. As more families from different parts of the world migrated to our university town and as we struggled as a community to appropriately and compassionately address social justice issues that arose in our school system, I hoped for confidence in my own competence to serve as a model of anti-racism, cultural understanding, and effective communication across humanly constructed boundaries. That confidence never really came.

\section{A University Community Committed to Cultural Competence}

Now as an assistant professor at a second university working with preservice teachers in the same school district in which I did my own small town student teaching, I find that I am looking for ways to give teacher candidates the depth of experience early in their careers that I found insufficient in my own. I am fortunate to work with a small group of learned colleagues who have spent many years cumulatively studying issues related to cultural competencies (Morrison, Robbins, \& Rose, 2008) necessary for teachers to successfully meet the needs of the diverse groups of students with whom they will work. As a part of a commitment to send teachers into the world who are culturally responsive and responsible, we require our students to explore their own cultural identities and to examine challenging dilemmas that help them unearth the assumptions that may block their full attention to the needs of their future students. As Howard's (2006) title proclaims, "We can't teach what we don't know," and many of us do not know how to address issues of race and ethnicity without some measure of discomfort and uncertainty.

Like me, my students are both blessed and cursed by the geographical limitations of this beautiful mountainous part of our state that is home to a largely Caucasian English-speaking population. Though some socioeconomic diversity and dialectic differences are easily noticeable in the local schools, racial, ethnic, and religious diversity is much more limited, especially outside the boundaries of the two small college towns that more readily draw faculty and students from other parts of the world. As others in similar situations have found, our teacher 
candidates are "overwhelmingly European American, middle-class, monolingual, White females who have had little sustained and substantive interactions with people of color" (Gay \& Kirkland, 2003, p. 182). Likewise, the field experiences available to them in our local community place them in situations to work with children who are mostly White, middle class, and English speaking. As a result, we find that our graduates would benefit from experiences that will naturally expose them to a broader world view and add incentive to build the competencies that some among them seem to think unnecessary. As a faculty, we make it a priority to intentionally create experiences, conversations, and requirements that nurture a mature understanding of multiculturalism in our graduates so that they are ready for the students and the classrooms they will encounter. In my experience, however, some of the students are not willing or able to fully acknowledge that need.

Fortunately, our university partners with two other institutions of higher education in an annual study abroad trip to Malawi. Malawi is a developing country in sub-Saharan Africa that remained under British rule until the mid1960s. Public primary education was opened to all children in 1994 with a transition from an autocratic president to a multi-party democracy. The onslaught of new enrollees has resulted in overcrowded classrooms and undertrained teachers throughout much of the country to this day (Englund, 2002).

For the few who are able to participate, the Malawi Study Abroad experience provides a unique opportunity for our students to work with children in a set of circumstances very different from our schools in the United States. I was fortunate to travel along with this group in 2008 for what turned out to be a rich cultural experience that has greatly influenced my own ability to live and teach with authenticity. What follows is a sampling of short vignettes based on journal notes and email messages sent to family and friends that have been reconstructed in the context of three key frameworks that are often used by researchers in reference to the process of building cultural competencies.

\section{Transformational Learning}

\section{Aha Malawi!: “Marketplace Communion” in Mid-June 2008}

On the bus trip to Zomba, we stopped at a romping market and I was nervous because l'd had an unpleasant experience with a pushy guy in Lilongwe and we'd been told, of course, not to buy or eat anything that could not be peeled. This is where the most amazing thing happened.... I was hanging back on the bus because we didn't want to leave folks' belongings unattended while the driver went to buy tomatoes. I was standing in the doorway of the bus when all of these beautiful Malawian women surrounded me with their wares upon their heads (peas, cauliflower, lettuce nothing that could be peeled - YIKES). I was thinking "Oh no, here 
we go!" They offered me their vegetables, but when I said "No, thanks," they didn't go away. They were smiling and talking to me in one of several local languages and after a few awkward moments, I realized that they just wanted to look at me and talk to me and then they began to try and teach me the words for their vegetables. It was so great! They smiled and coaxed and prodded and laughed at me as I laughed at myself for my feeble attempts at the language. It was so much fun. I just can't really describe it. And then, one woman moved closer up to me with an outstretched bunch of cauliflower and I thought "Oh, she's going to try again to sell me something", but instead she said in slow, but very clear English, "A gift for you, my friend." I turned to the driver (who was back from his tomato run) and said, "What do I do? Do I give her money?" He said, "Say, Zikomo" (Thank you). Then another woman came forward and gave me a big bunch of lettuce and said, "A gift for you, my friend." I almost cried right then and there. It was like communion. I have never felt more blessed. To think I thought that I was coming here to give something to these people! $\mathrm{Ha}$ ! They also proceeded to tell me in sign language how to wash and cut the vegetables and mix it with nsima (kind of thick corn porridge). We stopped a little while down the road at a village where the children came running several hundred yards up from their homes yelling and jumping for joy when they saw us. We gave the vegetables that I had received from the women to those children since, after all, I could not really cook them in order to eat them.

This brief interaction came to be one of the most memorable from my trip as I thought through the power of the moment in which my presumptions about the women's intentions were shaken when I was told to do something that I have been taught to do all my life - say "Thank you." I thought the women wanted something from me, and I was beginning to get my defenses up because we had already had so many experiences with pushy vendors that I was not prepared for the act of simple connection and kindness offered by these women. It was an important lesson for me.

\section{Defining and Nurturing Transformations}

What happened to me here was a transformative experience - an "Aha moment." What Butler (2000) describes as the "Aha!" that results from a "mindbody experience" in reference to overcoming a difficult physical challenge by moving from disequilibrium and frustration to success can be equally applied in the reverse when an event occurs that helps us to quickly overcome a mental challenge or cognitive block that we may not even recognize in ourselves. We can likewise feel a "body-mind" jolt of consciousness that is at first disorienting but becomes more comfortable as we assimilate new understandings into a 
familiar world view. Cognitive and emotional growth are closely intertwined (Butler, 2000) in both situations. This is what happened to me during my "Marketplace Communion" episode. Because of the openness and genuineness of a group of women in a country foreign to me, I moved from distrust to joy and gratitude within a brief moment of recognition. This first trip to Malawi was filled with many such moments for me as well as for other faculty and students with whom I traveled.

Mezirow (2000) defines a "disorienting dilemma" such as mine as one that "sets in motion a self-examination of one's underlying assumptions, followed by sharing these thoughts with others, which leads to exploring new roles, relationships, and actions, a trying on of new roles, and, finally, a re-integration into one's life on the basis of conditions dictated by one's new perspective" ( $p$. 22). Although Mezirow's theory has been criticized for its very Westernized focus on rationality (Merriam \& Ntseane, 2008), it may indeed describe what happens to Westerners like myself when faced with unfamiliar circumstances. Duffy (2001) interprets Mezirow's transformative learning as an experience that adjusts problematic mindsets and assumptions in order to make us more capable of change. After disorientation and self-assessment, learners seek respected colleagues and friends to process their experience aloud. With support from those who can help the learner think critically about previous perspectives and new awakenings, new "habits of mind" can be adopted (Mezirow, 2003). I have told and retold my Marketplace Communion story many times. Each time, I am reminded of my need to be open to the possibilities of the present moment without judgment or preconception.

Through a process of disequilibrium, followed by conversation, reconsideration, and assimilation, we are changed (Mezirow, 2003). "Transformation theory's focus is on how we learn to negotiate and action our purposes, values, feelings and meanings rather than those we have uncritically assimilated [emphasis added] from others - to gain greater control over our lives as socially responsible, clear-thinking decision makers" (Mezirow, 2000, p. 8). Deissler (2008) applies this to the responsibility of teachers to "remain cognizant of the importance of [their] beliefs, and not just their practice... (and to) become familiar with the theory of transformational learning to make use of it as an invaluable tool for investigation into the process of belief change and the design of experiences for teachers that encourage such a change" (p. 96). As teachers of teachers, university professors have the responsibility to create purposefully disorienting situations that can jolt our students into new ways of thinking, believing, and acting. As Feldman (2003) states, "For us to change how we teach requires us to change who we are as teachers" (p. 27). Educators must embrace new ways of challenging themselves to think differently about the world they live in and how that world affects the educational experiences of their students. Indeed, educators would benefit from deconstructing their own identities in order to better understand differences that students may bring to the classroom and how they may best serve all of those students. When a richer understanding of any society and its influences on education systems is 
uncovered, educators may guide students to more productive participation in those societies (Taylor, 2007).

\section{Critical Pedagogy}

\section{Aha Malawi!: “Classroom Confusion” in Late June 2008}

On Friday, one of the students came to get me to help her because the kids were "going crazy and whacking each other over the head." The standard one (grade one) teacher had not shown up that day, but the children were there anyway. This seems to happen a lot. Imagine that!

The student had sent the children out to break so she could come to get help. When we got back to the room and called the children inside, they started whacking each other again. Remember that we are talking about approximately 120 children! I went over to the ones who were being particularly naughty and pointed at them one by one with my most severe "principal face." They got the message and sat down promptly along with the others. Lest you think I was some kind of miracle worker and therefore successful in gaining order, listen to the rest of the story....

Remember that these children don't speak English at this age so we were working entirely with gestures. We were able to communicate that we wanted them to make a circle, but instead of one big circle, they made four "small" ones (still about 30 each). I asked the student what she had planned and she had some plastic bottles cut in half that the teacher had said that she wanted to use to practice counting. There weren't nearly enough bottles to do much with (about 10 total) so we sent them outside again on "break". (Can you imagine a teacher really doing this every time they have a problem or don't know what to do?!)

We pow-wowed and came up with a game just selecting various children to throw the bottles in and out of the circle while others counted in unison. They seemed pleased with this and remained orderly and interested for quite some time. Then, silly me, I decided that we had milked that for all we could so we should try something different. I tried to tell them to stand up in their circles so we could do a song and dance game. HA! All h--- broke lose again! My principal face didn't work this time so I asked the student how much longer they were to be in school (everyone dismisses at different times). She said "15 minutes" so I asked her how to tell them to go home and she said, "Say, 'Goodbye 
children"'. Soooo, we said "Goodbye children" and they all raced for the door.

All I can say is that they at least had a couple of clueless adults with them doing something for a few minutes that day instead of no adult with them and doing nothing that day.

\section{Defining and Nurturing Critical Reflection}

As you can tell from the tone I took in that reflection, I made quite a few judgments about what we encountered that day. I was more than a little bit incredulous that no adult teacher had bothered to come to school and that no employee of the school seemed to notice. I did not really consider the fact that the teacher knew that we were there to help and assumed that we were capable of doing so. Critical pedagogy insists that we look deeply at situations encountered to recognize when we are inserting our own view of the world into a situation inappropriately. We must gain perspective by thinking about the assumptions we bring to the situation and the viewpoint of other individuals whom we are judging with our Western middle class outlook (Allen \& HermannWilmarth, 2004; Gay \& Kirkland, 2003, Tamura, Nelson, \& Ford-Stevenson, 1996). My worldview as a former school principal holds that teachers are to come to school except in a dire emergency in which they would communicate as necessary with plans left for a substitute. This system of thinking was simply not in play during this episode.

Other concepts central to critical pedagogy include finding models of success (Ladson-Billings, 1995), building community, and acting for change (Nieto, 2000; Villegas \& Lucas, 2002). In this classroom situation, we had to act in the moment based on who we were and what we knew, but as I plan to return to Malawi in 2010, it is important that I seek to understand how those who are successful in the school setting there do what they do with a different set of resources than those to which I am accustomed. How does that teacher who has been at the school for 50 years engage the students in their daily lessons? He has their rapt attention at every turn. I have seen this first hand.

By seeking genuine connection and community with the teachers there, we can learn what is needed and we can think together about how to best act for the good of the children in a manner that is culturally sensitive and respectful. Instead of coming to the schools with plans to engage with the classroom set on the terms that we know, it would serve us well to ask the teachers what they expect from us and what they wish for us to do while we are there. At the same time, we might ask them to let us know if they are not coming to school so that we can voice with humility our ineptitude for handling a situation that they take for granted every day.

Critical pedagogy for cultural competence prescribes that we engage in reflective thinking and writing about situations we encounter that we do not 
understand. We must explore our own histories and acknowledge different groups to which we and others belong (Allen \& Hermann-Wilmarth, 2004). We must visit unfamiliar communities with appreciation while our eyes and ears are focused on definitions and models of success in that setting and, when appropriate, we must participate in reforming institutions of oppression (Gay, 2000; Villegas \& Lucas, 2002), but only with the participation and guidance of the oppressed.

\section{Service Learning}

\section{Aha Malawi!: The Malawi Chibale Project in Early July 2008}

Chibale /che bal lay/ means "relationship" in Chichewa, one of the national languages of Malawi. We were introduced to the term by one of the workers at the inn where we stay on our travels to Malawi for study abroad each summer. We asked him to help us find a word for "friendship" when seeking to officially name the project that grew out of a small donation brought along by one of the students in the Summer 2007 group. The donation became the seed money for a feeding program at one of the three schools visited by the three American universities. Relationships were the key to the formation of the study abroad collaboration among three institutions of higher education, a collaboration that was built from a foundation of collegiality among university faculty who had established close connections with school leaders in Malawi. Strong relationships also keep the students who travel connected with one another and with their new Malawian friends so that they continue to support the feeding program along with a scholarship program and a project to support girls' education with their time and money even after they return home.

\section{Defining and Nurturing Learning through Service}

The International Center for Service Learning in Teacher Education (ICSLTE) defines service learning as "a teaching and learning strategy that integrates meaningful community service with instruction and reflection to enrich the learning experience, teach civic responsibility, and strengthen communities" (ICSLTE, 2010, para. 1). Service learning is built on the power of relationships in which common goals are reached for in a spirit of "mutuality and solidarity" (Baker-Boosamra, Guevara, \& Balfour, 2006; King 2004). Key standards in a service learning project include well-defined learning objectives, a spirit of solidarity, and positive outcomes for all (Baker-Boosamra, Guevara, \& Balfour, 2006; King 2004). The Malawi Chibale project is an initiative begun with input from the teachers at one of the schools in which we serve. The project is kept 
afloat by the leadership of teachers and community members who manage the funds provided by their U.S. partners throughout the year. The goal is for the adult students from the U.S. to learn first-hand lessons about social injustices and to act in small ways toward correcting those injustices in partnership with the people affected by them (Crabtree, 2008). Service learning goals are only accomplished when parties on all sides reap the benefits of learning and community. Camphia-Bacote (2003) discusses how students in international study abroad experiences are often surprised to realize that while they go with the intention of giving to the people they encounter, they are, in fact, given so much more in return. Service learning principles make this balance a priority. "By living the experience, the students develop a heightened awareness of human needs globally, emphasizing involvement for positive impact...A concern for civic responsibility is newly ignited as opportunities to develop citizenship skills to achieve social change are recognized" (Camphia-Bacote, 2003, p. 208). Yet, actions that are taken must happen in the context of mutuality and community where the server and the served benefit equally from genuine relationships and respect for one another.

\section{Aha Malawi: A Trifold Perspective}

Research in transformational learning theory, critical pedagogy, and service learning each offer important perspectives on the successful implementation of study abroad programs like the Malawi experience described here. This analysis is limited to a shorthand description of each of those theories that does not do justice to the extensive empirical evidence and theoretical basis of any one of them. There are large bodies of research examining international field experiences through each of those lenses independently. In my view, however, there is value in creating a single abridged lens through which to look at all of these perspectives simultaneously in order to build stronger field experiences that encompass the wisdom of all three. Perhaps the three theoretical frameworks offered might each be judiciously honed down to four essential components as follows.

A. Transformational learning requires:

1. a disorienting event, followed by

2. conversation and reflection, an opportunity to

3. reconsider a previously held perspective and finally to

4. assimilate new learning with old.

B. Critical pedagogy is characterized by:

1. gaining perspective on the limits of one's own experience 
2. finding models of success within a culture different from one's own

3. building community with diverse others

4. acting for change.

C. Service learning principles include an adherence to:

1. learning objectives

2. mutuality

3. solidarity

4. positive outcomes for all involved.

These twelve key elements are arguably streamlined from the extensive work of researchers in these three fields of study and are represented even more briefly in Figure 1 to better illustrate the potential for interplay among them.

Figure 1: Interrelated Frameworks

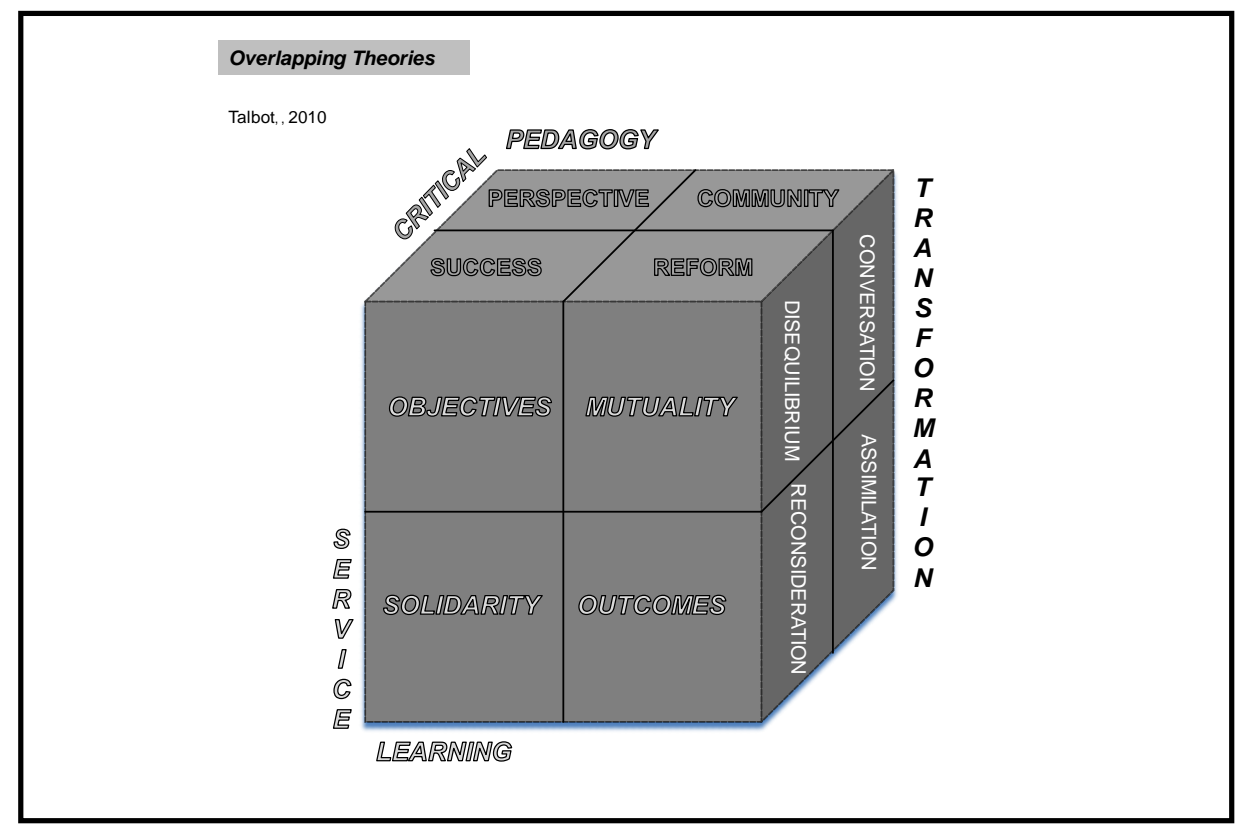

Indeed this model begins to visually represent the priorities of the three theories simultaneously. However, the complexity of the multifaceted cube seems unwieldy and impractical for immediate application by practitioners. To further articulate and refine these perspectives into a useful lens that can be applied to the context of cultural field experience for pre-service teachers requires some significant modification and attention to the substantial harmony of thought among the theories. 
In a 2008 article proposing a structure to achieve "transformative sustainability" in international settings, Sipos, Batisti, and Grimm (2008) emphasize the importance of "engaging head, hands and heart" in study visits by "balancing cognitive, psychomotor and affective domains" (p.1). For our purposes, one might attach the notion of the "head" in a tri-fold conceptual model to critical pedagogy as a reminder that deep thinking and learning are essential for building cultural competencies. The "heart" might be associated with transformational learning as we connect to the emotional experience of being moved by passion into new understandings. The "hands" are aptly associated with service as they represent the real work and actions that must take place for any substantive change. The work of the hands emphasized strongly in service learning, the critical reflection of the mind emphasized also in critical pedagogy, and the disorienting event that affects the heart vividly apparent in transformational learning should be honored in balance with one another in an effective field experience as in all of life. Figure 2 illustrates a framework for understanding the significant overlap and interaction among these themes with less redundancy. As seen here, while some concepts are unique to each theory, there are important commonalities as well. Strong emphases on reflection, community, and change are apparent from all three perspectives.

Figure 2: Engaging Head, Hands and Heart

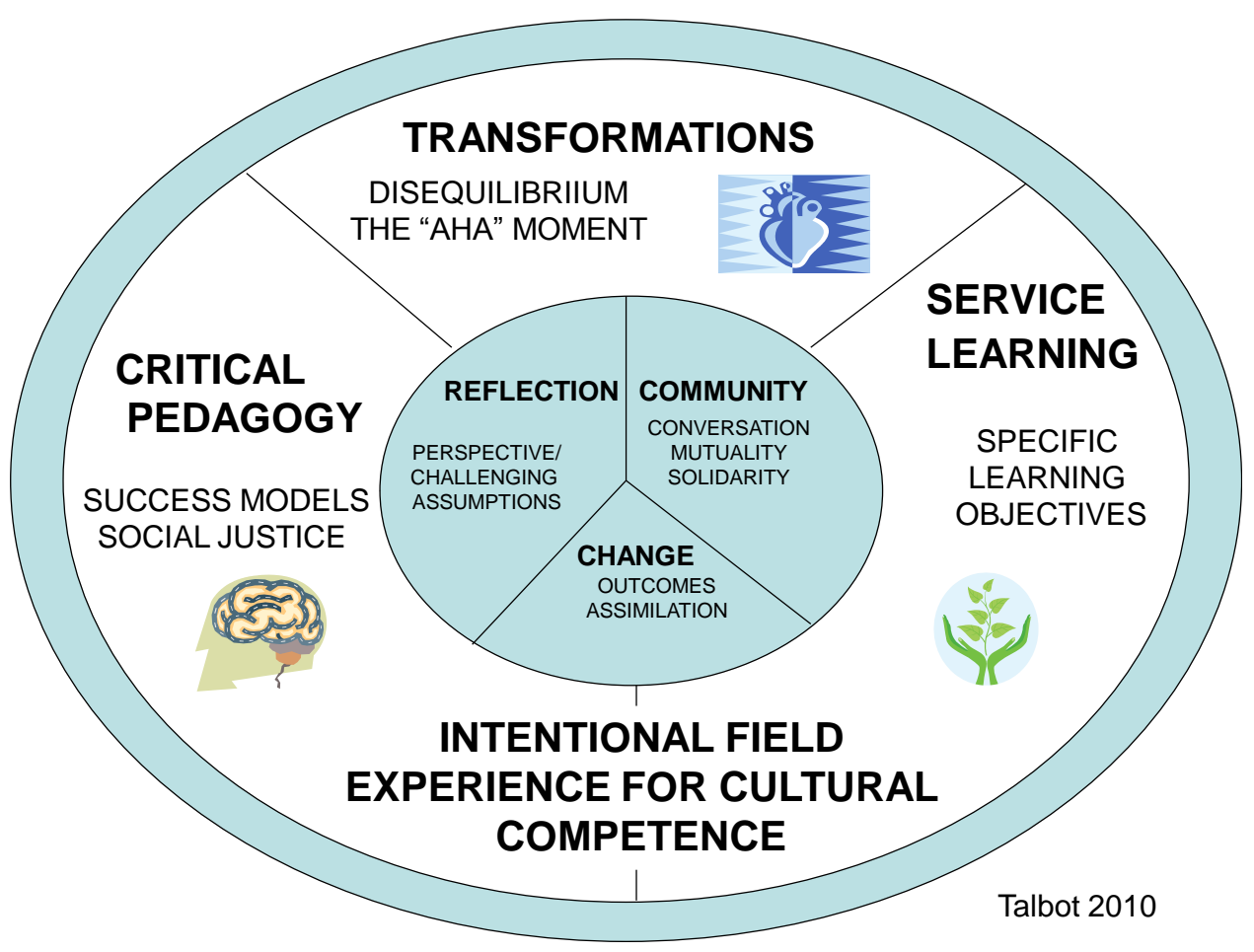




\section{Practical Applications}

As illustrated in Figure 2, the intersection of transformational theory, critical pedagogy, and service learning seems to rest in engagement of the head, hands, and hearts of participants in a simultaneous focus on community, reflection, and change. Specific steps that teacher educators can take to ensure attention to these priorities in planning field experiences deliberately designed to build cultural competencies might include the following.

A. Community Priorities such as:

1. Locating settings for field experiences that are culturally unfamiliar for students and have the potential for surprises.

2. Nurturing relationships with individuals in those communities who are willing to participate in creating common goals that meet real needs for students and the community.

3. Identifying success models in that community and making intentional connections for the students.

B. Reflective Priorities such as:

1. Formalizing the critical reflection process that is essential to critical pedagogy (i.e., making critical writing and conversation a key component before, during, and after diverse field experiences.)

2. Requiring reading and reflection about social justice dilemmas as part of the process and using guiding questions to help students "go deep."

C. Change Priorities such as:

1. Experimenting, assessing, and taking action for improvement.

2. Changing personal and institutional habits of mind and habits of practice.

Table 1 presents a time-based structure for addressing these priorities before, during, and after an intentional cultural field experience like the Malawi Study Abroad. 
Table 1: Implementation Framework

\begin{tabular}{|c|c|c|c|}
\hline & Community & Action & Reflection \\
\hline Before & $\begin{array}{l}\text { Identify field placement } \\
\text { with disorienting } \\
\text { potential. } \\
\text { Seek input from the } \\
\text { host community prior to } \\
\text { visit. }\end{array}$ & $\begin{array}{l}\text { Determine objectives } \\
\text { for projects of mutual } \\
\text { benefit and potential for } \\
\text { sustainability. }\end{array}$ & $\begin{array}{l}\text { Anticipate: "Pre- } \\
\text { flection" based on } \\
\text { personal experience, } \\
\text { orientation sessions, } \\
\text { and reading. }\end{array}$ \\
\hline During & $\begin{array}{l}\text { Find and acknowledge } \\
\text { models of success } \\
\text { within the community. } \\
\text { Engage in deliberate } \\
\text { conversations and } \\
\text { experiences to build } \\
\text { mutual relationships } \\
\text { between local } \\
\text { community members } \\
\text { and project participants. }\end{array}$ & $\begin{array}{l}\text { Work/Take action for } \\
\text { socially responsible } \\
\text { change. } \\
\text { Experience/embrace } \\
\text { disorienting dilemmas } \\
\text { as they occur naturally. }\end{array}$ & $\begin{array}{l}\text { Observe, converse and } \\
\text { challenge assumptions: } \\
\text { reflection guided by } \\
\text { structured questions. }\end{array}$ \\
\hline After & $\begin{array}{l}\text { Seek feedback from } \\
\text { community members. } \\
\text { Communicate at } \\
\text { regular intervals about } \\
\text { project plans and } \\
\text { priorities before the } \\
\text { next visit. }\end{array}$ & $\begin{array}{l}\text { Work with community to } \\
\text { plan next steps. } \\
\text { Maintain ongoing } \\
\text { connections. }\end{array}$ & $\begin{array}{l}\text { Assimilate and change: } \\
\text { "Retro-flection." }\end{array}$ \\
\hline
\end{tabular}

\section{Implications and Recommendations}

To become a culturally competent teacher, one must experience situations that demand the competencies developed through critical reflection, transformational opportunities, and service to others. Ideally, these situations will happen for students long before they set foot in a classroom that requires that they are prepared for whomever they find there. Field settings close to home, wherever that may be, might not be enough. Perhaps students who grow up in urban areas need to experience what it is like to teach in a rural community. Perhaps students who grow up in rural areas need to experience an urban setting. Perhaps we could all benefit from an international setting far different from our home country as our world becomes more globally interdependent. The more unfamiliar the experience, the more likely we are to find opportunities for 
disequilibrium and that "Aha moment" that can follow with careful reflection and personal growth.

Field experiences that can help this "Aha moment" occur take much preparation and adequate funding as well as safety precautions and support. Because "[t]eachers' own background experiences and preparation are key to what they bring to their teaching" (Vavrus, 2002, p.173), it is important to consider ways to address these needs. Even if it is unrealistic to believe that all teacher candidates will be able to travel internationally, it is a worthy goal for each one to have some experience in a setting unfamiliar enough to force an encounter with some new cultural phenomena. If distant travel is not possible, our students will be well served when we look for exchange opportunities closer to home and use technology connections to facilitate cross-cultural relationships (Phillion, Miller, \& Lehman, 2005). The results of purposeful transformational service learning in a context of critical pedagogy could be powerful indeed.

\section{References}

Allen, J., \& Hermann-Wilmarth, J. (2004). Cultural construction zones. Journal of Teacher Education, 55, 214 - 226.

Baker-Boosamra, M., Guevara, J., \& Balfour, D. (2006). From service to solidarity: Evaluation and recommendations for international service learning. Journal of Public Affairs Education, 12(4), 479-500.

Butler, S. (2000). Aha! The almost predictable outcome of a mind-body experience. Zip Lines: The Voice for Adventure Education, 41, 45-46.

Camphia-Bacote, J. (2003). The process of cultural competence in the delivery of healthcare services: A culturally competent model of care $\left(4^{\text {th }}\right.$ ed.). Cincinnati, OH: Transcultural CARE Associates.

Crabtree, R. D. (2008). Theoretical foundations for international service learning. Michigan Journal of Community Service Learning, 15(1), 18-36.

Deissler, C. H. (2008). Changing beliefs versus changing concepts: Transformational learning as a tool for investigating and encouraging teacher belief change. Educational Media and Technology Yearbook, 33, 91-99.

Duffy, M. (2001). A critique of cultural education in nursing. Journal of Advanced Nursing, 36(4), 487-495.

Englund, H. (Ed.). (2002). A democracy of chameleons: Politics and culture in the new Malawi. Blantyre, Malawi: Christian Literature Association. 
Feldman, A. (2003). Validity and quality in self-study. Educational Researcher, 32(3), 26-28.

Gay, G. (2000). Culturally responsive teaching: Theory, research and practice. New York: Teachers College Press.

Gay, G., \& Kirkland, K. (2003). Developing cultural critical consciousness and self-reflection in pre-service teacher education. Theory into Practice, 42(3), 181-187.

Howard, G. (2006). We can't teach what we don't know. New York: Teachers College Press

International Center for Service Learning in Teacher Education. (2010). Retrieved from http://educationprogram.duke.edu/service-learning.

King, J. T. (2004). Service-Learning as a site for critical pedagogy: A case of collaboration, caring, and defamiliarization across borders. Journal of Experiential Learning, 26(3), 121-137.

Ladson-Billings, G. (1995). But that's just good teaching! The case for culturally relevant pedagogy. Theory into Practice, 34(3), 161-165.

Merriam, S. B., \& Ntseane, G. (2008). Transformational learning in Botswana: How culture shapes the process. Adult Education Quarterly, 58(3), 183197.

Mezirow, J. (2000). Learning as transformation: Critical perspectives on a theory in progress. San Francisco: Jossey Bass.

Mezirow, J. (2003). Transformative learning as discourse. Journal of Transformative Education, 1(1), 58-63.

Morrison, K., Robbins, H., \& Rose, D. (2008). Operationalizing culturally relevant pedagogy: A meta-synthesis of classroom-based research. Equity and Excellence in Education, 41(4), 433 - 452.

Nieto, S. (2000). Placing equity front and center: Some thoughts on transforming teacher education for a new century. Journal of Teacher Education, 51(3), 180-187.

Phillion, J., Miller, P., \& Lehman, J. (2005). Providing field experiences with diverse populations for preservice teachers: Using technology to bridge distances and cultures. Multicultural Perspectives, 7(3), 3-9. 
Sipos, Y., Batisti, B., \& Grimm, K. (2008). Achieving transformative sustainability learning: Engaging head, hands and heart. International Journal of Sustainability in Higher Education, 9(1), 68-86.

Tamura, L., Nelson, P., \& Ford-Stevenson, T. (1996). Preparing teachers to recognize multiple perspectives. Paper presented to the Annual meeting of the American Association for Colleges of Teacher Education. Retrieved from ERIC database. (ED399235)

Taylor, E. W. (2007). An update of transformative learning theory: A critical review of the empirical research (1999-2005). International Journal of Lifelong Education, 26(2), 173-191.

Vavrus, M. (2002). Transforming the multicultural education of teachers: Theory, research, and practice. New York: Teachers College Press.

Villegas, A. M., \& Lucas, T. (2002). Preparing culturally responsive teachers: Rethinking the curriculum. Journal of Teacher Education, 53(1), 20-32. 